\title{
The incidence and characteristics of silent cerebral infarction in elderly diabetic patients: association with serum-soluble adhesion molecules
}

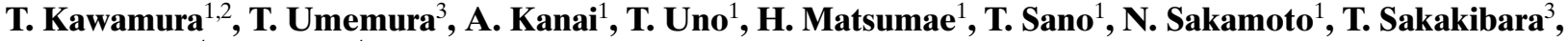 \\ J. Nakamura ${ }^{4}$, N. Hotta ${ }^{4}$ \\ ${ }^{1}$ Department of Metabolism and Endocrine Internal Medicine, Chubu Rosai Hospital, Nagoya, Japan \\ ${ }^{2}$ Research and Consultation Department of Health Service Center, Chubu Rosai Hospital, Nagoya, Japan \\ ${ }^{3}$ Department of Neurology, Chubu Rosai Hospital, Nagoya, Japan \\ ${ }^{4}$ Third Department of Internal Medicine, Nagoya University School of Medicine, Nagoya, Japan
}

\begin{abstract}
Summary The purpose of this study was to investigate the relationship between complications arising from silent cerebral infarction (SCI) and changes in the levels of serum-soluble adhesion molecules in 82 elderly diabetic patients aged 60 years and older. SCI was found in $43 \%$ of the 82 patients, with incidence increasing in relation to age. The prevalence of SCI was higher in subjects with hypertension, poor metabolic control and increased fibrinolysis. The levels of soluble intercellular adhesion molecule-1 (sICAM-1), vascular cell adhesion molecule-1 (sVCAM-1) and E-selectin (sE-selectin) were higher in diabetic patients than in non-diabetic subjects $(p<0.05, p<0.001$, and $p<0.05$, respectively). Also, sICAM-1 and sVCAM-1 were found at increased levels in diabetic patients with SCI compared to those without SCI ( $p<0.01$ and $p<0.05$, respectively). In particular, the level of sICAM-1 was increased in patients with SCI due to perforating arterial occlusion,
\end{abstract}

while the level of sVCAM-1 was increased in patients with SCI due to cortical arterial occlusion. However, no significant difference was found in sE-selectin levels. Overall average of the intima and media thickness (IMT) of the common carotid arteries increased with age. IMT proved to be greater in patients with SCI than in patients without SCI $(p<0.05)$, and showed a weak but significant positive correlation with sVCAM-1, while no correlation was found with either sICAM-1 or sE-selectin levels. In conclusion, measurement of serum adhesion molecules may be useful for diagnosing the early stages of brain damage and for prophylactic treatment which may prevent the onset or progression of SCI. [Diabetologia (1998) 41: 911-917]

Keywords Silent cerebral infarction, adhesion molecules, ICAM-1, VCAM-1, E-selectin, carotid artery, diabetes mellitus.
Received: 15 December 1997 and in revised form: 3 March 1998

Corresponding author: T. Kawamura, M.D., Research and Consultation Department of Health Service Center, Chubu Rosai Hospital, 1-10-6 Komei, Minato-ku, Nagoya 455, Japan Abbreviations: SCI, Silent cerebral infarction; sICAM-1, soluble intercellular adhesion molecule-1; sVCAM-1, soluble vascular cell adhesion molecule-1; sE-selectin, soluble E-selectin; MRI, magnetic resonance image; FLAIR, fluid-attenuated inversion recovery; IMT, intima and media thickness; FBG, fasting blood glucose; T-chol, total cholesterol; HDL-chol, HDLcholesterol; TG, triglycerides; $\beta$-TG, $\beta$-thromboglobulin; PF4 , platelet factor-4; TAT, thrombin antithrombin complex; PIC, plasminogen $\alpha 2$ plasmin inhibitor complex; Lp(a), lipoprotein (a).
It has been widely accepted that the initial steps in the formation of atherosclerotic lesions involve the adherence of circulating leukocytes to dysfunctional endothelium and their subsequent transmigration into the arterial intima [1-3]. The recruitment of leukocytes into the tissues is dependent on a multistep cascade of events mediated by distinct adhesion molecules such as the selectin family, immunoglobulin superfamily and integrin family [3, 4]. Substantially, vascular cell adhesion molecule-1 (VCAM-1) has been found in rabbit atherosclerotic lesions [5] and intercellular adhesion molecule-1 (ICAM-1) has been expressed in human atherosclerotic plaques [6] and carotid bifurcations [7]. Also, the soluble form of adhesion molecules has recently been found in serum and increased levels have been re- 
ported in a variety of diseases [8]. Although the physiological or pathophysiological role of the soluble forms is unclear, it is possible they may serve as monitors of pathological conditions, reflecting the physiological response resulting from tissue destruction, and that they may have physiological activity.

On the other hand, increased soluble adhesion molecules have also been reported in diabetic patients [8-13] and, in addition, more recent reports have suggested that levels of soluble adhesion molecules, sVCAM-1 in particular, may be useful as a marker for development of microangiopathy [14] and for the presence of atherosclerotic lesions [15]. However, few studies have reported on adhesion molecules in diabetic patients with macrovascular disease resulting from atherosclerosis $[13,15]$ and none regarding the relationship of these molecules to the high incidence of stroke in diabetic patients. Since the increasing elderly diabetic population is expected to cause a steady rise in the incidence of cerebrovascular disease, studies regarding its early diagnosis are of great importance, in order to prevent the disease.

Recently, detection of asymptomatic cerebral infarction discovery has become easier due to increased availability of magnetic resonance imaging (MRI) [16-20]. This type of stroke (silent cerebral infarction [SCI]) is considered to be the preclinical stage for symptomatic stroke and vascular dementia [17-19]. The most potent risk factors for SCI have been reported to be hypertension and aging [16, 17, 19-21], along with diabetes $[17,18,21]$.

We therefore performed MRI in elderly diabetic patients aged 60 years or greater, and investigated the incidence and characteristics of SCI, particularly concerning the association with serum-soluble adhesion molecules as a potential predictor of SCI.

\section{Subjects, materials and methods}

Patients. We studied 82 elderly outpatients with Type II (noninsulin-dependent) diabetes mellitus who were older than 60 years of age and without history or clinical symptoms of cerebrovascular disease, and no neurological deficits. The subjects consisted of 35 men (67.1 \pm 1.0 years) and 47 women $(71.4 \pm 1.0$ years) whose ages ranged from 60 to 84 years (mean of $69.7 \pm 0.7$ years). Sixty percent of these subjects had hypertension, $49 \%$ had hyperlipidaemia, and $20 \%$ had neither. All subjects underwent neurological examination by a neurologist. As control subjects, 41 age- and sex-matched non-diabetic subjects (mean, 69.2 \pm 0.8 years; 16 male, $67.1 \pm$ 1.0 years; 25 female, $70.6 \pm 1.1$ years) were selected, of whom $61 \%$ were patients with hypertension and/or hyperlipidaemia ( $44 \%$ ), and $22 \%$ were healthy volunteers with neither. The average value of $\mathrm{HbA}_{1 \mathrm{c}}$ was $5.0 \pm 0.1 \%$, ranging from 4.5 to $5.5 \%$ in control subjects. Informed consent was obtained from each of the participants, and the study was performed in accordance with the principles of the Declaration of Helsinki.
Table 1. Clinical and biochemical characteristics of elderly diabetic patients with and without SCI

\begin{tabular}{|c|c|c|c|}
\hline & Overall & with SCI & $\begin{array}{l}\text { without } \\
\text { SCI }\end{array}$ \\
\hline $\begin{array}{l}\text { No. of patients } \\
\text { (male/female) }\end{array}$ & $82(33 / 49)$ & $35(14 / 21)$ & $47(19 / 28)$ \\
\hline Age (years) & $69.7 \pm 0.7$ & $71.8 \pm 1.1$ & $68.0 \pm 0.9^{\mathrm{b}}$ \\
\hline $\begin{array}{l}\text { Duration of diabetes } \\
\text { (years) }\end{array}$ & $13.2 \pm 1.0$ & $13.9 \pm 1.2$ & $12.6 \pm 1.4$ \\
\hline Body mass index $\left(\mathrm{kg} / \mathrm{m}^{2}\right)$ & $23.0 \pm 0.4$ & $23.5 \pm 0.6$ & $22.7 \pm 0.5$ \\
\hline T-cholesterol (mmol/l) & $5.40 \pm 0.09$ & $5.32 \pm 0.14$ & $5.46 \pm 0.11$ \\
\hline $\begin{array}{l}\text { HDL-cholesterol } \\
(\mathrm{mmol} / \mathrm{l})\end{array}$ & $1.49 \pm 0.04$ & $1.45 \pm 0.05$ & $1.53 \pm 0.06$ \\
\hline Triglycerides (mmol/l) & $1.54 \pm 0.07$ & $1.51 \pm 0.11$ & $1.57 \pm 0.10$ \\
\hline Lipoprotein (a) (mg/l) & $207 \pm 25$ & $225 \pm 44$ & $194 \pm 30$ \\
\hline $\begin{array}{l}\text { Fasting blood glucose } \\
(\mathrm{mmol} / \mathrm{l})\end{array}$ & $7.97 \pm 0.21$ & $8.43 \pm 0.36$ & $7.62 \pm 0.24$ \\
\hline $\mathrm{HbA}_{1 \mathrm{c}}(\%)$ & $7.0 \pm 0.1$ & $7.3 \pm 0.2$ & $6.8 \pm 0.1^{\mathrm{b}}$ \\
\hline $\begin{array}{l}\text { Fasting serum immuno- } \\
\text { reactive insulin (pmol/l) }\end{array}$ & $60.8 \pm 4.3$ & $58.0 \pm 4.3$ & $62.9 \pm 6.9$ \\
\hline$\beta$-thromboglobulin $(\mu \mathrm{g} / \mathrm{l})$ & $52.2 \pm 4.0$ & $51.0 \pm 5.3$ & $53.0 \pm 5.8$ \\
\hline Platelet factor-4 $(\mu \mathrm{g} / \mathrm{l})$ & $15.9 \pm 2.2$ & $14.9 \pm 3.1$ & $16.7 \pm 3.1$ \\
\hline $\begin{array}{l}\text { Thrombin antithrombin } \\
\text { complex }(\mu \mathrm{g} / \mathrm{l})\end{array}$ & $2.7 \pm 0.3$ & $3.6 \pm 0.7$ & $1.9 \pm 0.1^{\mathrm{a}}$ \\
\hline $\begin{array}{l}\text { Plasminogen } \alpha 2 \text { plasmin } \\
\text { inhibitor complex }(\mathrm{mg} / \mathrm{l})\end{array}$ & $0.89 \pm 0.04$ & $1.04 \pm 0.08$ & $0.78 \pm 0.04^{\mathrm{a}}$ \\
\hline D-dimer $(\mathrm{mg} / \mathrm{l})$ & $0.45 \pm 0.05$ & $0.60 \pm 0.10$ & $0.34 \pm 0.04^{\mathrm{a}}$ \\
\hline Fibrinogen $(\mu \mathrm{mol} / \mathrm{l})$ & $8.39 \pm 0.31$ & $8.82 \pm 0.45$ & $8.07 \pm 0.41$ \\
\hline Haematocrit (\%) & $40.5 \pm 0.4$ & $39.8 \pm 0.7$ & $40.9 \pm 0.5$ \\
\hline Hypertension (+/-) & $49 / 33$ & $27 / 8$ & $22 / 25^{\mathrm{a}}$ \\
\hline $\begin{array}{l}\text { Cigarette smoking } \\
\text { (Never/past/current) }\end{array}$ & $49 / 16 / 17$ & $20 / 8 / 7$ & 29/8/10 \\
\hline $\begin{array}{l}\text { Diabetic microvascular } \\
\text { complications }(+/-)\end{array}$ & $23 / 59$ & $10 / 25$ & $13 / 34$ \\
\hline $\begin{array}{l}\text { Treatment } \\
\text { (Diet/OHA/Insulin) }\end{array}$ & $25 / 43 / 14$ & $7 / 20 / 8$ & $18 / 23 / 6$ \\
\hline
\end{tabular}

Values represent the mean \pm SEM. ${ }^{\mathrm{a}} p<0.01,{ }^{\mathrm{b}} p<0.05$, significantly different from diabetic subjects with SCI. Diabetic microvascular complications (+): patients with at least one diabetic complication; OHA, oral hypoglycaemic agents

Evaluation of subjects. Blood samples were obtained with a 19gauge butterfly needle without stasis while the patients were in a fasting state. A variety of parameters (Table 1) were measured and serum was stored at $-70^{\circ} \mathrm{C}$ until assay of adhesion molecules. Biochemicals such as total cholesterol (T-chol), HDL cholesterol (HDL-chol), triglycerides (TG), and fasting blood glucose (FBG) were measured by autoanalyser using routine enzymatic techniques. Beta-thromboglobulin (BetaTG), platelet factor-4 (PF-4), thrombin antithrombin complex (TAT), plasminogen $\alpha 2$ plasmin inhibitor complex (PIC), and D-dimer were analysed using enzyme-immunoassay. Lipoprotein(a) ( $\mathrm{Lp}(\mathrm{a}))$ was measured by latex agglutination immunoturbidimetric assay. $\mathrm{HbA}_{1 \mathrm{c}}$ (normal range: 4.3-5.8\%) was measured by latex enhanced competitive immunoturbidimetric assay. Plasma insulin was assayed by RIA. For plasma fibrinogen assay, the Dade thrombin-clotting time methodology was used. Hypertension was defined by either prior diagnosis, current treatment with an antihypertensive agent, or blood pressure 
greater than $165 / 95 \mathrm{mmHg}$ on three consecutive measurements.

Assessment of atherosclerosis. SCI was diagnosed using MRI (Signa Horizon, GE, 1.5 Tesla; Milwaukee, Wisconsin, USA), and the criteria used for diagnosis were: irregular areas of high signal intensity larger than $3 \mathrm{~mm}$ in diameter detected on T2-weighted images, low signal intensity areas on T1-weighted images, and areas of higher intensity than cerebrospinal fluid in proton density images or fluid attenuated inversion recovery (FLAIR) images. Lesions less than $3 \mathrm{~mm}$ in diameter or lesions with signal intensity similar to cerebrospinal fluid in proton images and FLAIR images were excluded because of a high possibility that they were enlarged perivascular spaces, even if they demonstrated a high signal on T2-weighted images and a low signal on T1-weighted images. We also excluded leukoaraioses (deep white matter hyperintensity) or deep white matter lesions detected only on T2-weighted images from this study. In addition, infarctions were classified into two groups based on the arterial territory of lesion indicated in the MR images: perforating and cortical arterial branch systems.

Ultrasonographic assessment of carotid artery wall thickness has become a standard technique for non-invasive visualization of atherosclerotic lesions [22-26]. We performed high resolution B-mode imaging of bilateral common carotid arteries using an ultrasound system with a $7.5-\mathrm{MHz}$ tranducer (SSA-260A; Toshiba Co., Tokyo, Japan). The average intima and media thickness (IMT) values were determined by the maximum thickness in plaque-free segments of each longitudinal projection as defined by Pignoli et al. [27].

Measurement of serum-soluble (s) adhesion molecules. Serum samples for determination of sICAM-1, sVCAM-1 and sE-selectin were analysed in duplicate using the single-step sandwich enzyme-linked immunosorbent assay method (R\&D Systems Europe, Abingdon, Oxon, UK) with Model 550 Microplate Reader (Bio Rad, Hercules, Calif., USA). Since increased levels of circulating adhesion molecules have been reported in a variety of diseases [8], subjects with malignancies, chronic and/or acute inflammatory disease, severe cardiovascular disease (such as myocardial infarction and unstable angina), severe microvascular complications (such as renal failure), and other pathological conditions known to increase adhesion molecules were excluded from this study.

Statistical analysis. Results are expressed as the mean \pm SEM. Statistical analysis was performed by analysis of variance, followed by an unpaired $t$-test for the comparison of two means, and a post hoc test for comparison among groups. The chisquare test for independence, simple regression and multivariate step-wise regression analysis were also used. These statistical analyses were carried out using Statview-J 4.5 on an Apple Macintosh. $P$ less than 0.05 was considered to be statistically significant.

\section{Results}

Comparison of clinical and biochemical characteristics between elderly diabetic patients with and without SCI (Table 1). SCI was revealed in $43 \%$ (35 of 82) of the elderly diabetic patients. The incidence of SCI increased with age: the incidences were $30 \%$ in the $60 \mathrm{~s}$ (13 of 43$), 53 \%$ in the $70 \mathrm{~s}$ (17 of 32 ), and $71 \%$ in the 80 s (5 of 7). Seventy-seven percent of the SCI lesions
Table 2. Comparison of sICAM-1, sVCAM-1 and sE-selectin between elderly non-diabetic and diabetic subjects with and without hypertension or hyperlipidaemia

\begin{tabular}{|c|c|c|c|c|}
\hline & $\begin{array}{l}\text { No. of } \\
\text { subjects }\end{array}$ & sICAM-1 & sVCAM-1 & $\overline{\text { sE-selectin }}$ \\
\hline \multicolumn{5}{|l|}{ Overall } \\
\hline Diabetic & $(82)$ & $249.8 \pm 10.5^{\mathrm{b}}$ & $783.8 \pm 19.0^{\mathrm{a}}$ & $54.3 \pm 2.3^{\mathrm{b}}$ \\
\hline Non-diabetic & (41) & $214.9 \pm 8.8$ & $678.7 \pm 23.5$ & $45.6 \pm 3.2$ \\
\hline \multicolumn{5}{|c|}{ with hypertension } \\
\hline Diabetic & $(49)$ & $252.5 \pm 12.6^{\mathrm{b}}$ & $808.0 \pm 27.0^{\mathrm{a}}$ & $55.2 \pm 3.0$ \\
\hline Non-diabetic & (25) & $209.3 \pm 10.6$ & $685.3 \pm 23.5$ & $47.2 \pm 4.5$ \\
\hline \multicolumn{5}{|c|}{ without hypertension } \\
\hline Diabetic & $(33)$ & $245.8 \pm 18.4$ & $747.8 \pm 24.0^{\mathrm{b}}$ & $53.1 \pm 3.7$ \\
\hline Non-diabetic & (16) & $223.6 \pm 15.6$ & $668.4 \pm 22.4$ & $43.0 \pm 4.6$ \\
\hline \multicolumn{5}{|c|}{ with hyperlipidaemia } \\
\hline Diabetic & $(40)$ & $254.0 \pm 15.5^{\mathrm{b}}$ & $753.4 \pm 19.0^{\mathrm{a}}$ & $51.7 \pm 3.0$ \\
\hline Non-diabetic & (18) & $193.5 \pm 14.6$ & $656.1 \pm 17.5$ & $42.6 \pm 3.7$ \\
\hline \multicolumn{5}{|c|}{ without hyperlipidaemia } \\
\hline Diabetic & $(42)$ & $245.7 \pm 14.4$ & $813.0 \pm 32.1^{\mathrm{b}}$ & $56.8 \pm 3.5$ \\
\hline Non-diabetic & (23) & $231.7 \pm 9.7$ & $696.4 \pm 26.1$ & $47.9 \pm 5.0$ \\
\hline
\end{tabular}

Values represent the mean $\pm \operatorname{SEM}(\mu \mathrm{g} / \mathrm{l}) .{ }^{\mathrm{a}} p<0.01,{ }^{\mathrm{b}} p<0.05$, significantly different from non-diabetic subjects

were considered to be in areas supplied mainly by the perforating arteries (if lesions were in areas supplied by both the perforating and cortical arteries, the predominant arterial system was selected). The average number of infarcts was $2.5 \pm 0.3$, with a single infarct present in $26 \%$ of the patients, two infarcts in $43 \%$, and three or more infarcts in $31 \%$.

Significant differences were observed in age, $\mathrm{HbA}_{1 \mathrm{c}}$, TAT, PIC, D-dimer and the presence of hypertension between elderly diabetic patients with and without SCI, as shown in Table 1 . In addition, we performed multivariate step-wise analysis for factors such as shown in Table 1, which revealed that the predictors for SCI were age, TAT and $\mathrm{HbA}_{1 \mathrm{c}}$ $\left(r^{2}=0.29, F=8.35, p<0.0001\right)$.

Comparison of SICAM, sVCAM and sE-selectin between elderly diabetic and non-diabetic subjects with and without hypertension or hyperlipidaemia (Table 2). Soluble ICAM-1, sVCAM-1 and sE-selectin were found at significantly increased levels in diabetic patients when compared to non-diabetic control subjects. Additionally, when levels of adhesion molecules were compared between diabetic and non-diabetic subjects with and without hypertension or hyperlipidaemia, levels of sVCAM-1 in diabetic subjects were significantly higher than those in non-diabetic subjects in any state, while levels of sICAM-1 were found to increase significantly in diabetic subjects with hypertension or hyperlipidaemia.

Comparison of serum-soluble adhesion molecules between elderly diabetic patients with and without SCI (Fig. 1, Table 3). Multivariate regression analysis of the levels of soluble adhesion molecules and other 
Table 3. Comparison of sICAM-1, sVCAM-1 and sE-selectin between elderly diabetic patients with and without hypertension and SCI

\begin{tabular}{llllll}
\hline & \multicolumn{2}{l}{ with Hypertension } & & \multicolumn{2}{l}{ without Hypertension } \\
\cline { 2 - 3 } \cline { 5 - 6 } $\begin{array}{l}\text { No. of } \\
\text { subjects }\end{array}$ & with SCI & without SCI & & with SCI & without SCI \\
sICAM-1 & $275.7 \pm 17.4$ & $224.0 \pm 16.6^{\mathrm{b}}$ & & $326.0 \pm 47.7$ & $220.1 \pm 16.5^{\mathrm{b}}$ \\
sVCAM-1 & $812.1 \pm 37.9$ & $803.0 \pm 38.9$ & & $886.1 \pm 46.3$ & $703.6 \pm 21.9^{\mathrm{a}, \mathrm{c}}$ \\
sE-selectin & $56.5 \pm 4.3$ & $53.5 \pm 4.3$ & $50.3 \pm 4.7$ & $54.0 \pm 4.7$ \\
\hline
\end{tabular}

Values represent the mean $\pm \operatorname{SEM}(\mu \mathrm{g} / \mathrm{l}) .{ }^{\mathrm{a}} p<0.01,{ }^{\mathrm{b}} p<0.05$, significantly different from diabetic patients with SCI. ${ }^{c} p<0.05$ significantly different from hypertensive diabetic patients without SCI

factors such as shown in Table 1 , revealed that the most potent predictor for SCI was SICAM-1 $\left(r^{2}=\right.$ $0.40, F=8.00, p<0.0001)$. As shown in Figure 1 , sICAM-1 was found at increased levels in patients with SCI compared to patients without SCI (287.2 \pm 17.3 vs $221.9 \pm 11.6 \mu \mathrm{g} / \mathrm{l}, p<0.005)$. In particular, the levels of sICAM-1 $(300.1 \pm 20.4 \mu \mathrm{g} / \mathrm{l})$ in patients with SCI due to perforating arterial occlusion showed a marked increase. In addition, sICAM-1 was positively correlated with the numbers of infarcts $(r=0.364$, $p<0.01)$. Serum levels of sVCAM-1 also increased in patients with SCI compared to those without SCI $(829.0 \pm 31.3$ vs $750.1 \pm 22.6 \mu \mathrm{g} / \mathrm{l}, p<0.05)$, and were found at increased levels $(889.0 \pm 82.3 \mu \mathrm{g} / \mathrm{l}, p<0.05)$ in patients with SCI due to cortical arterial occlusion in contrast with sICAM-1. However, we could not observe any significant differences in sE-selectin levels in patients with and without SCI $(55.1 \pm 3.5,53.8 \pm$ $3.2 \mu \mathrm{g} / \mathrm{l}$, respectively).

We also investigated the association between levels of each adhesion molecule and various factors such as aging, hypertension, microalbuminuria, and metabolic control in elderly diabetic patients. Soluble VCAM-1, but neither sICAM-1 nor sE-selectin, was found to increase significantly with aging $(r=0.347$, $p<0.005)$. We did not find any significant differences in sICAM-1, sVCAM-1 and sE-selectin between diabetic patients with and without hypertension or hyperlipidaemia (Table 2), and increased levels of sICAM-1 were observed in patients with SCI regardless of the presence of hypertension (Table 3 ) and hyperlipidaemia (data not shown). Since we excluded patients with advanced complications such as renal failure and proliferative retinopathy, the association with microvascular complications could not be fully examined in the present study. However, sVCAM-1 showed a significant increase in 21 patients with microalbuminuria, including two patients with overt proteinuria, compared with patients without such symptoms $\quad(847.7 \pm 39.6$ vs $758.9 \pm 20.7 \mu \mathrm{g} / \mathrm{l}, \quad p<$ $0.05)$. Only sE-selectin correlated positively with $\mathrm{HbA}_{1 \mathrm{c}}$ pertinent to diabetic control $(r=0.259, p<$ 0.05). Among the adhesion molecules, sICAM-1
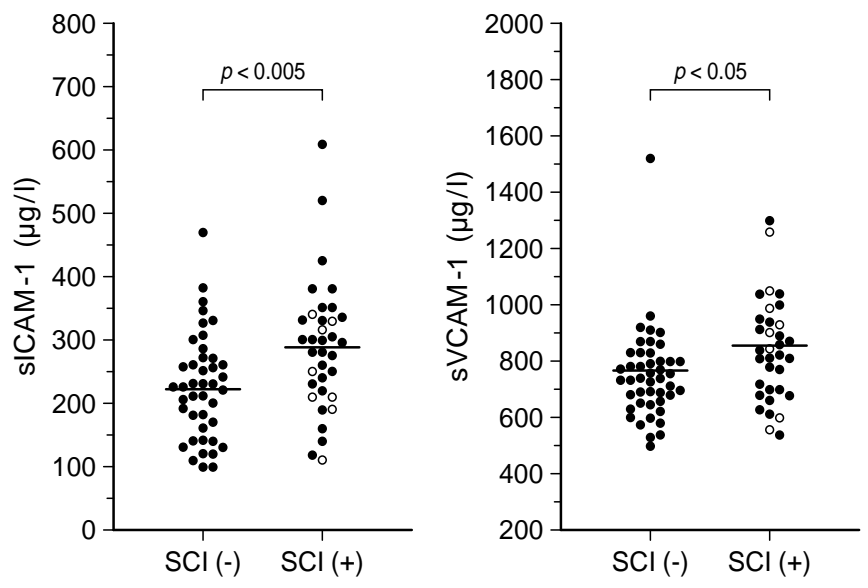

Fig. 1. Comparison of sICAM-1 and sVCAM-1 between elderly diabetic patients with $(+)$ and without $(-)$ SCI. Infarcts due to perforating arterial system $(\mathbf{)})$ and cortical arterial system $(\bigcirc)$ in diabetic patients with SCI. Bar shows mean value
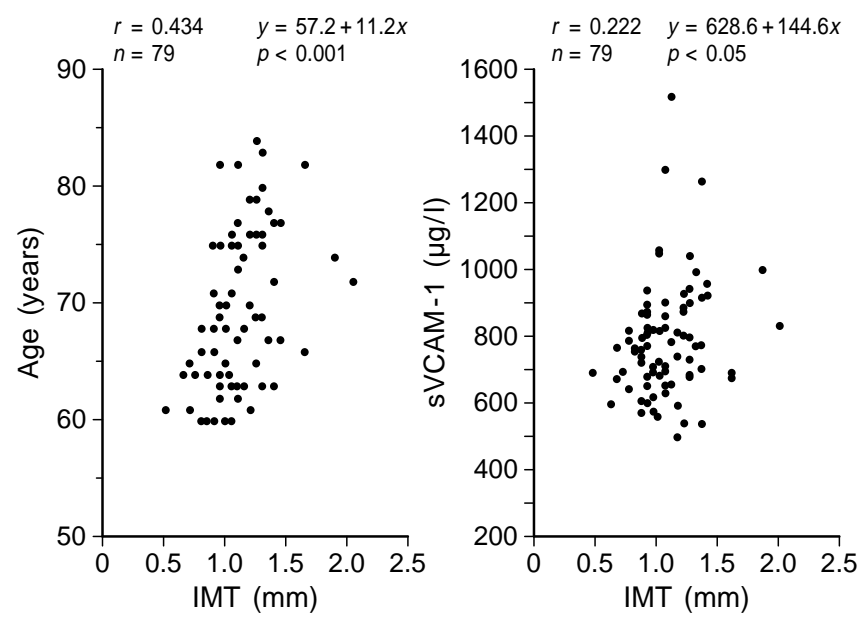

Fig. 2. Relationship between IMT and age or sVCAM-1 in elderly diabetic patients

showed a weak, positive correlation with sE-selectin $(r=0.253, p<0.05)$.

IMT in elderly diabetic patients (Fig. 2). The overall average of IMT was $1.11 \pm 0.03 \mathrm{~mm}$, and IMT increased with age from $1.02 \pm 0.04 \mathrm{~mm}$ in the $60 \mathrm{~s}$, and $1.21 \pm 0.05 \mathrm{~mm}$ in the $70 \mathrm{~s}$, to $1.26 \pm 0.08 \mathrm{~mm}$ in the $80 \mathrm{~s}$. Also, IMT in patients with SCI $(1.18 \pm 0.05 \mathrm{~mm})$ was significantly thicker than in patients without SCI $(1.05 \pm 0.04 \mathrm{~mm}, p<0.05)$. Among serum soluble adhesion molecules, only sVCAM- 1 showed a weak but significant positive correlation with IMT as shown in Figure 2. There was no relationship between IMT and metabolic control, hypertension, or hyperlipidaemia. 


\section{Discussion}

The elderly population is gradually increasing in developed countries, and it is predicted that the number of elderly diabetic patients will also increase [28]. The management of macrovascular complications will therefore play a more important role in relation to mortality and quality of life in elderly diabetic patients than it does currently, since aging itself is a risk factor for vascular breakdown.

On the other hand, the advent of neuroimaging, especially the prevalence of MRI, has focused medical attention on the frequency of unexpected white matter lesions such as SCI in the brain. It is well known that hypertension along with aging [16, 17, 19-21, 29, 30] are strong risk factors for the onset of SCI, while it is controversial whether impared glucose tolerance may be a risk factor for SCI [16-19, 21]. Moreover, it remains undecided whether SCI predisposes patients to symptomatic stroke as well [17-19]. Kobayashi et al. [29] have reported that cerebral blood flow is decreased in neurologically normal adults with SCI. Also, SCI is reported to be related to impaired cognition [31] and depression [32]. Consequently, it is likely that progression of SCI may lead to vascular dementia. In addition, it has been reported that diabetic patients have a very high risk of death resulting from stroke [33], indicating that the severity of stroke in diabetic subjects is much greater than that in normal subjects because of cumulative risk factors. Thus, the importance of early prevention of strokes in diabetic patients cannot be overly stressed.

First, we investigated the general risk factors for stroke, and discovered that age, hypercoagulable state, accelerated fibrinolysis, the presence of hypertension and poor metabolic control were risk factors for SCI. Our observations that the incidence of SCI increased with age and was higher in hypertensive patients than in normotensive patients were in agreement with many previous reports. Moreover, interestingly, diabetic patients with SCI had poorer metabolic control compared with patients without SCI, indicating that metabolic control itself may affect the incidence of SCI, since $\mathrm{HbA}_{1 \mathrm{c}}$ seems to reflect not only current but also consecutive glycaemic control. This may be supported by the reports that hyperglycaemia induces cerebrovascular ischaemia [34] or that metabolic control of diabetes is an important predictor of stroke in elderly subjects [35].

Recently, there have been several reports concerning ischaemic cerebrovascular disease and adhesion molecules, especially ICAM-1 [36-41]. Sobel et al. [36] have demonstrated the existence of ICAM-1 antigen in vessels situated within the infarction zone of stroke patients. A new concept for the onset of ischaemic stroke has been proposed in recent reports as follows: ICAM-1 is expressed on the cell surface by exposure to cytokines such as tumour necrosis factor- $\alpha$ and interleukin- $1 \beta$ during ischaemia [42] or by free radicals induced after reperfusion [39], which contributes not only to neutrophil adherence to the endothelial cells but also to the migration and infiltration of neutrophils. This vicious circle of neutrophils and ICAM-1 may physically plug and obstruct the microvasculature [38, 39, 43, 44]. However, most of these reports describe the expression and changes in adhesion molecules during the acute stroke phase [41] or under experimental ischaemic conditions [38, 44], and nothing has been reported on alterations in adhesion molecules under chronic conditions such as SCI. In addition, although increased serum-soluble adhesion molecules have also been reported in diabetic patients [8-13], few detailed reports are available on the role of adhesion molecules in diabetic patients with cerebrovascular disease where diabetes is considered to be a risk factor. Our present study showed that an increased level of adhesion molecules was found in elderly diabetic patients in comparison with age- and sex-matched non-diabetic control subjects, and was in accordance with previous reports [8-13, 45]. Such increased levels of adhesion molecules found in diabetic patients may be explained by recent reports that advanced glycation end-products, caused by hyperglycaemia [46] and increased thromboxane $\mathrm{A}_{2}$ resulting from abnormal prostaglandin metabolism [47, 48], induced the expression of ICAM-1 and VCAM-1. Multiple risk factors likely to be found in diabetic patients, such as hypertension [49], hyperlipidaemia [12] and a diabetic predisposition to thrombosis, may also contribute to the expression of adhesion molecules.

Subsequently, we investigated the association between adhesion molecules and SCI. Multivariate regression analysis showed sICAM-1 to be the most potent predictor for SCI. As shown in Figure 2, significantly increased levels of sICAM-1 were found in patients with SCI, especially that caused by perforating arterial occlusion, compared with those without SCI. Lipohyalinosis and angionecrosis induced by hypertension are generally considered to explain the mechanism by which infarction of perforating arterial branch systems occurs. However, increased levels of sICAM-1 were observed in diabetic patients with SCI regardless of the presence of hypertension (Table 3). Accordingly, it is likely that contributions of other factors such as increased levels of SICAM-1 in addition to hypertension may also be thought to cause the onset of perforating arterial infarction.

On the other hand, although SVCAM-1 was also found at higher levels in patients with SCI compared with those without SCI, there were no differences between the two groups in diabetic patients with hypertension. In addition, our present study showed that only sVCAM-1 increased with age and also had a weak but significant positive correlation with IMT 
which also strongly correlated with age. These results are in complete agreement with reports by Otsuki et al. [15]. Interestingly, sVCAM-1 was found at increased levels in patients with SCI due to cortical arterial occlusion which is generally considered to be caused by atherosclerosis. Taken together, it seems likely that an increased level of sVCAM-1 may strongly suggest the existence of atherosclerotic lesion related to aging.

Regarding sE-selectin, there were no siginificant differences found in the comparison of patients with and without SCI, and only sE-selectin was found to correlate with diabetic control.

In conclusion, the levels of serum-soluble adhesion molecules were found to increase in elderly diabetic patients, indicating that an increased level of sVCAM-1 may be suggestive of advanced atherosclerosis related to aging, while an increased level of sICAM-1 may reflect the presence of SCI or contribute to the onset. Thus, more increased levels of adhesion molecules in diabetic patients than in non-diabetic subjects may be responsible for the accelerated development of macrovascular complications. Therefore, treatments to decrease the levels of adhesion molecules may prevent the progression of macrovascular complications. However, further studies will be required to verify these results.

Acknowledgements. We thank N. Kajita and H. Nishio for their excellent technical assistance and preparation of the manuscript.

\section{References}

1. Ross R (1986) The pathogenesis of atherosclerosis- an update. N Engl J Med 314: 488-500

2. Editorials (1992) Atherosclerosis goes to the wall. Lancet 339: 647-648

3. Collins T (1993) Biology of disease. Endothelial nuclear factor-kB and the initiation of the atherosclerotic lesion. Lab Invest 68: 499-508

4. Carter AM, Grant PJ (1997) Vascular homeostasis, adhesion molecules, and macrovascular disease in non-insulindependent diabetes mellitus. Diabet Med 14: 423-432

5. Cybulsky MI, Gimbron Jr MA (1991) Endothelial expression of mononuclear leukocyte adhesion molecule during atherogenesis. Science 251: 788-791

6. Poston RN, Haskard DO, Coucher JR, Gall NP, JohnsonTidey RR (1992) Expression of intercellular adhesion molecule-1 in atherosclerotic plaques. Am J Pathol 140: 665-673

7. Endres M, Laufs U, Merz H, Kaps M (1997) Focal expression of intercellular adhesion molecule- 1 in the human carotid bifurcation. Stroke 28: 77-82

8. Gearing A J H, Newman W (1993) Circulating adhesion molecules in disease. Immunol Today 14: 506-512

9. Gearing A J, Hemingway I, Pigott R, Hughes J, Rees AJ, Cashman SJ (1992) Soluble forms of vascular adhesion molecules, E-selectin, ICAM-1, and VCAM-1: pathological significance. Annals NY Acad Sci 667: 324-331

10. Steiner M, Reinhardt KM, Krammer B, Ernst B, Blann AD (1994) Increased levels of soluble adhesion molecules in type 2 (non-insulin dependent) diabetes mellitus are independent of glycaemic control. Thromb Haemostasis 72: 979-984

11. Roep BO, Heidenthal E, de Vries RRP, Kolb H, Martin S (1994) Soluble forms of intercellular adhesion molecule-1 in insulin-dependent diabetes mellitus. Lancet 343: 1590-1593

12. Cominacini L, Pasini AF, Garbin U et al. (1995) Elevated levels of soluble E-selectin in patients with IDDM and NIDDM: relation to metabolic control. Diabetologia 38: 1122-1124

13. Fasching P, Waldhäusl W, Wagner OF (1996) Elevated circulating adhesion molecules in NIDDM - potential mediators in diabetic macroangiopathy. Diabetologia 39: 1242-1244 (Letter)

14. Fasching P, Veitl M, Rohac M, Streli, Schneider B, Waldhäusl W, Wagner OF (1996) Elevated concentrations of circulating adhesion molecules and their association with microvascular complications in insulin-dependent diabetes mellitus. J Clin Endocrinol Metab 81: 4313-4317

15. Otsuki M, Hashimoto K, Morimoto Y, Kishimoto T, Kasayama S (1997) Circulating vascular cell adhesion molecule-1 (VCAM-1) in atherosclerotic NIDDM patients. Diabetes 46: 2096-2101

16. Awad IA, Spetzler RF, Hodak JA, Awad CA, Carey R (1986) Incidental subcortical lesions identified on magnetic resonance imaging in the elderly. I. Correlation with age and cerebrovascular risk factors. Stroke 17: 1084-1089

17. Lechner H, Schmidt R, Bertha G, Justish E, Offenbacher $\mathrm{H}$, Schneider (1988) Nuclear magnetic resonance image white matter lesions and risk factors for stroke in normal individuals. Stroke 19: 263-265

18. Kase CG, Wolf PA, Chodosh EH et al. (1989) Prevalence of silent stroke in patients presenting with initial stroke: The Framingham study. Stroke 20: 850-852

19. Jørgensen HS, Nakayama H, Raaschou HO, Gram J, Olsen TS (1994) Silent infarction in acute stroke patients. Prevalence, localization, risk factors and clinical significance: The Copenhagen stroke study. Stroke 25: 97-104

20. Shinkawa A, Ueda K, Kiyohara Y et al. (1995) Silent cerebral infarction in a community-based autopsy series in Japan. The Hisayama study. Stroke 26: 380-385

21. Tuszynski MH, Petito CK, Levy D (1989) Risk factors and clinical manifestations of pathologically verified lacunar infarctions. Stroke 20: 990-999

22. Handa N, Matsumoto M, Maeda H et al. (1990) Ultrasonic evaluation of early carotid atherosclerosis. Stroke 21: 1567-1572

23. Kawamori R, Yamasaki Y, Matsushima H et al. (1992) Prevalence of carotid atherosclerosis in diabetic patients. Ultrasound high-resolution B-mode imaging on carotid arteries. Diabetes Care 15: 1290-1294

24. Hougaku H, Matsumoto M, Handa N et al. (1994) Asymptomatic carotid lesions and silent cerebral infarction. Stroke 25: 566-570

25. Pujia A, Gnasso A, Irace C, Colonna A, Mattioli P (1994) Common carotid arterial wall thickness in NIDDM subjects. Diabetes Care 17: 1330-1336

26. Yamasaki Y, Kawamori R, Matsushima H et al. (1995) Asymptomatic hyperglycemia is associated with increased intimal plus medial thickness of the carotid artery. Diabetologia 38: 585-591

27. Pignoli P, Tremoli E, Poli A, Oreste P, Paoletti R (1986) Intimal plus medial thickness of the arterial wall: a direct measurement with ultrasound imaging. Circulation 74: 1399-1406 
28. Ohmura T, Ueda K, Kiyohara Y et al. (1993) Prevalence of type 2 (non-insulin-dependent) diabetes mellitus and impaired glucose tolerance in the Japanese general population: the Hisayama study. Diabetologia 36: 1198-1203

29. Kobayashi S, Okada K, Yamashita K (1991) Incidence of silent lacunar lesion in normal adults and its relation to cerebral blood flow and risk factors. Stroke 22: 13791383

30. Hougaku H, Matsumoto M, Kitagawa K et al. (1992) Silent cerebral infarction as a form of hypertensive target organ damage in the brain. Hypertension 20: 816-820

31. Matsubayashi K, Shimada K, Kawamoto A, Ozawa T (1992) Incidental brain lesions on magnetic resonance imaging and neurobehavioral functions in the apparently healthy elderly. Stroke 23: 175-180

32. Fujikawa T, Yamawaki S, Touhouda Y (1993) Incidence of silent cerebral infarction in patients with major depression. Stroke 24: 1631-1634

33. Tuomilehto J, Rastenyte D, Jousilahti P, Sarti C, Vartiainen E (1996) Diabetes mellitus as a risk factor for death from stroke. Stroke 27: 210-215

34. Kawai N, Keep RF, Betz AL (1997) Hyperglycemia and the vascular effects of cerebral ischemia. Stroke 28: 149-154

35. Kuusisto J, Mykkanen L, Pyorala K, Laakso M (1994) Noninsulin-dependent diabetes and its metabolic control are important predictors of stroke in elderly subjects. Stroke 25: $1157-1164$

36. Sobel RA, Mitchell ME, Fondren G (1990) Intercellular adhesion molecule-1 (ICAM-1) in cellular immune reactions in the human central nervous system. Am J Pathol 136: $1309-1316$

37. Hess DC, Zhao W, Carroll J, McEachin M, Buchanan K (1994) Increased expression of ICAM-1 during reoxygenation in brain endothlial cells. Stroke 25: 1463-1468

38. Okada Y, Copeland BR, Mori E, Tung M-M, Thomas WS, del Zoppo GJ (1994) P-selectin and intracellular adhesion molecule-1 expression after focal brain ischemia and reperfusion. Stroke 25: 202-211

39. Matsuo Y, Yamasaki Y, Kogure K (1996) Inflammatory reaction after brain damage and prospective therapy against damage impending cerebral infarction. Keio J Med 45: 270-274

40. Lindsberg PJ, Carpén O, Paetau A, Karjalainen-Lindsberg M-L, Kaste M (1996) Endothelial ICAM-1 expression associated with inflammatory cell response in human ischemic stroke. Circulation 94: 939-945

41. Shyu K-G, Chang H, Lin C-C (1997) Serum levels of intercellular adhesion molecule-1 and E-selectin in patients with acute ischaemic stroke. J Neurol 244: 90-93

42. Liu T, Clark RK, McDonnell PC et al. (1994) Tumor necrosis factor- $\alpha$ expression in ischemic neurons. Stroke 25: 1481-1488

43. Clark WM, Madden KP, Rothlein R, Zivin JA (1991) Reduction of central nervous system ischemic injury in rabbits using leukocyte adhesion antibody treatment. Stroke 22: $877-883$

44. del Zoppo GJ, Schmid-Schönbein GW, Mori E, Copeland BR, Chang C-M (1991) Polymorphonuclear leukocytes occlude capillaries following middle cerebral artery occlusion and reperfusion in baboons. Stroke 22: 1276-1283

45. Schmidt AM, Crandall J, Hori O, Cao R, Lakatta E (1996) Elevated plasma levels of vascular cell adhesion molecule1 (VCAM-1) in diabetic patients with microalbuminuria: a marker of vascular dysfunction and progressive vascular disease. Br J Haematol 92: 747-750

46. Schmidt AM, Hori O, Chen JX et al. (1995) Advanced glycation endproducts interacting with their endothelial receptor induced expression of vascular cell adhesion molecule-1 (VCAM-1) in cultured human endothelial cells and in mice. J Clin Invest 96: 1395-1403

47. Yokote K, Morisaki N, Zenibayashi M et al. (1993) The phospholipase-A2 reaction leads to increased monocyte adhesion of endothelial cell via the expression of adhesion molecules. Eur J Biochem 217: 723-729

48. Ishizuka T, Suzuki K, Kawakami M et al. (1994) DP-1904, a specific inhibitor of thromboxane A2 synthesizing enzyme, suppresses ICAM-1 expression by stimulated vascular endothelial cells. Eur J Pharmacol 262: 113-123

49. Blann, AD, Tse W, Maxwell S Jr, Waite MA (1994) Increased levels of the soluble adhesion molecule E-selectin in essential hypertension. J Hypertension 12: 925-928 